\title{
Nanoscale mechanical properties and microstructure characterization of ultra-high performance fiber reinforced concrete materials
}

\author{
Lu xiaoli ${ }^{1}$, Li liping ${ }^{2}$, Li dan ${ }^{1}$ \\ 1.Wuhan University of Engineering Science, Wuhan, 432700 \\ ${ }^{2}$ China University of Geosciences (Wuhan) , Wuhan, 432700
}

\begin{abstract}
The construction of foundation engineering is developing towards high-rise and long-distance direction, and is facing more and more severe environmental threats. Traditional ordinary concrete materials have become increasingly difficult to meet these requirements. Ultra-high performance fiber concrete not only has higher mechanical properties than ordinary concrete, but also has better working performance and durability. Therefore, it can meet the requirements of high-rise, lightweight, intersection and longevity of building structures. The macro properties of materials obtained in different preparation processes are different. The microstructure research of materials links the preparation process with the macro properties from a scientific point of view. Fiber mixing improves the basic mechanical properties and impact fatigue performance of concrete, especially the effect of rigid fiber on improving the mechanical properties of concrete is significant. At the micro level, the fiber can inhibit the formation and development of microcracks. After the microcracks merge into macro cracks, the fibers restrict the crack development and increase the toughness and ductility.
\end{abstract}

\section{Introduction}

With the further deterioration of human living environment and the urgent need to develop and utilize unknown space, the basic engineering construction is developing towards high-rise and long-distance direction, and it is increasingly difficult for traditional ordinary concrete materials to face severe environmental threats [1]. Flexible fiber concrete with compressive strength greater than $100 \mathrm{MPa}$ and tensile strength greater than $10 \mathrm{MPa}$ is defined as ultra-high performance fiber concrete [2]. With the continuous development of human society and the continuous progress of science and technology, more and more high-rise structures, long-distance structures and heavy machinery structures are presented in modern architectural models, which require higher and higher working and mechanical properties of materials. The application of modern concrete structure engineering should not only meet the mechanical performance requirements, but also meet the long-term service performance requirements [3]. Generally speaking, in order to obtain high strength of ultra-high performance concrete, coarse aggregate is removed in the design of mixing ratio. The huge demand and consumption of cement aggravates the deterioration of ecological environment, and deviates from the basic principles of energy saving and low carbon sustainability to a certain extent. Ultra-high performance fiber reinforced concrete (UHPC) has become a hot spot in academic research because of its excellent mechanical properties and durability. It is widely used in civil engineering, architecture, water conservancy, transportation, tunnels, bridges, national defense protection and other fields with special requirements for structure and performance [4].

Under the premise of cement usage, producing ultra-high performance concrete of the same quality and ensuring the huge usage of concrete in my country's urbanization construction projects is an important topic for researchers all over the world. Instead of quartz sand, Jiao et al. studied the effects of ordinary river sand and different curing temperatures on the mechanical properties of ultra-high performance fiber concrete [5]. $\mathrm{Fu}$ studied the impact on the mechanical properties of ultra-high performance fiber concrete and found that because the fibers are easily dispersed in the pouring direction, the bending performance of the ultra-high performance fiber concrete beam perpendicular to the concrete flow direction is stronger [6]. Gao experimentally studied the mechanical properties of reactive powder concrete when mixed with different fiber volume ratios [7]. Lin et al. studied the influence of fiber volume ratio on the failure toughness and failure energy of concrete [8]. The excellent strength and ductility of 
ultra-high performance fiber concrete are closely related to the disorderly distribution of fibers in concrete [9]. On the microscopic level, the fiber has the function of inhibiting the formation and development of microcracks, and after microcracks merge and develop into macroscopic cracks, the fiber restricts the development of cracks and increases toughness and ductility [10]. Ultra-high performance fiber concrete not only has higher mechanical properties than ordinary concrete, but also has stronger working performance and durability. Therefore, it can meet the requirements of high-rise building structure, lightweight, crossover, and longevity, and has broad application prospects.

\section{Mechanical properties of fiber reinforced concrete}

With the increase of the world population and the improvement of human's material living standard, human's demand for natural resources and energy is increasing. On the other hand, the increasing waste discharged by human activities has destroyed the global ecological balance and seriously affected the living environment of human beings. The foundation of concrete strength depends on the strength and cooperation of various components, and the development of concrete strength depends on curing age, temperature and humidity conditions in curing city. The strength of concrete includes compressive strength, tensile strength and folding strength. Compressive strength is the basis of determining concrete strength grade. Aggregates with good quality and grade can improve the density of concrete, workability of fresh concrete and strength and durability after hardening. With the increase of fiber volume mixing ratio, the initial crack stress and deflection increase slightly, but the width is not large. When the fiber volume mixing ratio increases by $1 \%$, the initial cracking stress of end bending, end flattening and wave fiber reinforced concrete increases on average respectively [11]. Commonly used deformed short fibers are bent at the end, flat at the end, wavy, etc., and deformed fibers with complex geometry can serve as better anchors in the process of pulling out concrete after cracking. The construction of high performance concrete must have strict quality management and guarantee system. When choosing input neurons, considering the research of domestic and foreign scholars on ordinary concrete strength machines, two factors, the actual strength of cement and water cost, are taken as input neurons. High performance concrete is not self-compacting concrete without vibration, and the strength and impermeability of high performance concrete without vibration will decrease.

When the concrete is far away or the air temperature changes obviously, the slump and expansion loss of concrete caused by ambient temperature changes or distance factors should be tested in detail from the back field to the front field. When a large amount of superplasticizer is injected, concrete can still have great fluidity under the condition of low gelatin content. When preparing high-strength concrete, the content of superplasticizer should be close to or equal to saturation. By applying the perspective of composite materials, the number, form and distribution of strengthening stages can be controlled, so as to control the microstructure and properties of composite materials, and other components can be added to expand the properties of materials. The fluidity of cement paste with the same high content but different content of mother liquor of three water reducing agents is compared, and the results are shown in Table 1 and Figure 1.

Table 1 Fluidity test data of cement paste with different admixture content

\begin{tabular}{|c|c|c|c|c|}
\hline $\begin{array}{c}\text { Fluidity of } \\
\text { cement } \\
\text { paste }\end{array}$ & $0.8 \%$ & $1.0 \%$ & $1.2 \%$ & $1.4 \%$ \\
\hline J1 & 185 & 190 & 210 & 225 \\
\hline J2 & 190 & 200 & 215 & 230 \\
\hline J3 & 185 & 195 & 220 & 245 \\
\hline
\end{tabular}

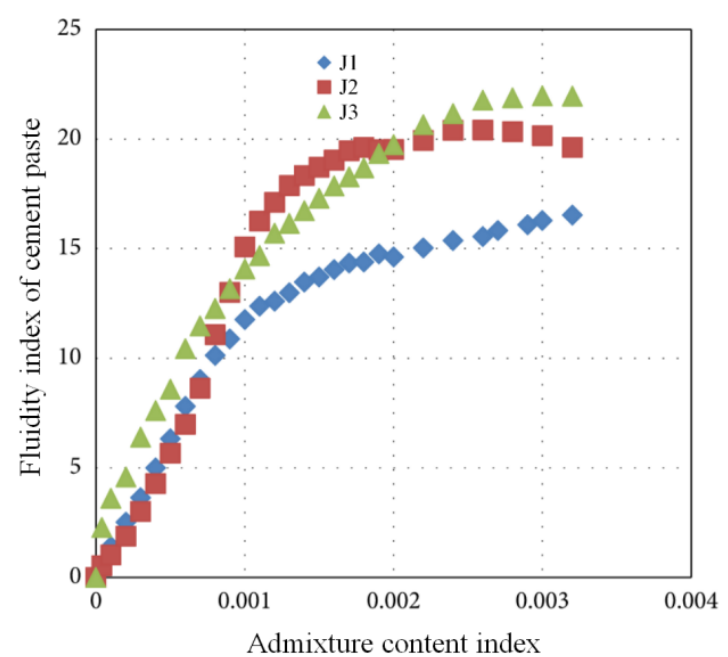

Fig. 1 Fluidity test data of cement paste with different water reducing agent content

By measuring the parameters of fresh concrete, the linear regression formula of the relationship between the composition of concrete mixture and the properties of hardened concrete is established:

$$
D_{i+1}(x)=\frac{D_{i}(x)}{Z_{i}}\left\{\begin{array}{cl} 
& e^{-a_{t}} \quad h_{i}(x)=y_{i} \\
e^{-a_{t}} & h_{i}(x) \neq y_{i}, D_{i}(x) \leq H W_{t} \\
e^{a_{t}} & h_{i}(x) \neq y_{i}, D_{i}(x)>H W_{t}
\end{array}\right.
$$

On the premise of standard curing, the compressive strength of concrete at different ages is predicted.

Logarithmic formula:

$$
A I_{t}=\frac{\left(I_{t}+Q_{t}\right)+\left(I_{t}+Q_{t}-D_{t}\right)}{2}=I_{t}+Q_{t}-\frac{D_{t}}{2}
$$

Slatter formula:

$$
f(x)=\operatorname{sign}\left[\omega^{T} x+b\right]
$$

Before the next layer of concrete solidifies for the first time, pour into the upper layer of concrete, and expand layer by layer from the lower part to keep 
horizontal stratification and injection uniformity. The ultimate goal of the preparation of high performance concrete is mainly excellent durability, which is used for load-bearing structures, and the strength should meet the requirements of different components at the same time. Ultrasonic CT is less harmful to human body and has a bright future in medical application. However, when applied to cement-based materials, the ultrasonic source has a large wavelength, and the ultrasonic wave is easy to diffract and refract. When the wavelength is small, the signal attenuation is faster. The strength of concrete includes compressive strength, tensile strength and folding strength. Compressive strength is the basis of determining concrete strength grade. High-quality graded aggregate can improve the density of concrete, improve the workability of newly emptied concrete and the strength and durability after hardening [12]. The strength of high performance concrete is inversely proportional to the total shrinkage. The higher the strength, the smaller the total shrinkage. However, if the initial strength of concrete is continuously improved, the initial shrinkage of high performance concrete will also increase accordingly.

\section{Microstructure analysis of high performance fiber reinforced concrete materials}

According to the investigation, the bending performance of fiber concrete can best reflect the strengthening effect of fiber, and fiber concrete mainly bears the bending stress of pavement, airport surface, wharf pavement, bridge deck, industrial land and other projects. Fiber reinforced concrete not only has higher mechanical properties than ordinary concrete under static and quasi-static conditions, but also has better performance under dynamic loads such as fatigue and impact load. Because the gray value difference between solid phase groups is not obvious, and the boundaries overlap to a certain extent, it is difficult to segment groups.

Under the same mixing ratio, the higher the cement strength, the higher the concrete strength. When cement strength is constant, concrete strength is mainly determined by water-cement ratio. The water cost is large, the strength of cement paste is low, and the strength of concrete also decreases. The design method of mixing ratio mainly considers improving the internal structure of concrete, improving durability and prolonging the service life of the structure. Generally, the quantitative standards of concrete mix ratio are absolute volume method and apparent density method [13]. Under the condition of a certain cement strength, the mortar strength is mainly determined by the quality and physical properties of sand. For concrete mixing water, river sand or machine-made sand with good quality should be selected first, and reasonable grain grading area should be selected to control the mud content and harmful substance content of sand. When controlling the construction quality of high performance concrete after construction, it is mainly to analyze whether the concrete formed by accepting the strength of high performance concrete can meet the construction and design requirements. When necessary, the factors affecting durability, permeability and cold resistance should be analyzed or improved.

Studying the strengthening mechanism of fiber reinforced concrete is essentially the theoretical basis for improving the physical and mechanical properties of concrete, and also the basis for the performance design of fiber reinforced concrete. Good concrete mix ratio should meet the technical requirements of concrete. Including durability requirements, etc. The most important technical requirements of double-track box girder of passenger dedicated line are high strength and good operability. Durability requirements include crack, anti-freezing, fire resistance, etc. Choose suitable admixtures, which must be checked and approved by relevant state departments and meet the standards before they can be applied. Table 2 is the cement index to be controlled.

Table 2 Cement index data

\begin{tabular}{|c|c|c|c|c|}
\hline $\begin{array}{c}\text { Cement } \\
\text { index }\end{array}$ & Fineness & $\begin{array}{c}\text { Initial } \\
\text { setting } \\
\text { time }\end{array}$ & $\begin{array}{c}\text { Compress } \\
\text { ive } \\
\text { strength }\end{array}$ & $\begin{array}{c}\text { Standard } \\
\text { consisten } \\
\text { cy water }\end{array}$ \\
\hline $\begin{array}{c}\text { Ordinary } \\
\text { portland } \\
\text { cement }\end{array}$ & $40 \mathrm{um}$ & 170 & 43.5 & 23.5 \\
\hline
\end{tabular}

Fiber reinforced concrete is a complex fiber reinforced composite material. The mixing law of composite mechanics is to simplify fiber reinforced concrete into two stages. One is the basic phase, that is, cement-based materials, also known as continuous phase. The other is dispersed phase, that is, fibers evenly distributed on gas materials. The addition of dispersed phase often makes the properties of composites higher than those of gas phase, so dispersed phase is also called reinforcing phase. The influence of aggregate decreases with the increase of water fee. This is because the strength of the slurry itself plays a major role. The relationship between compressive strength and age of concrete prepared with different aggregates is shown in Figure 2.

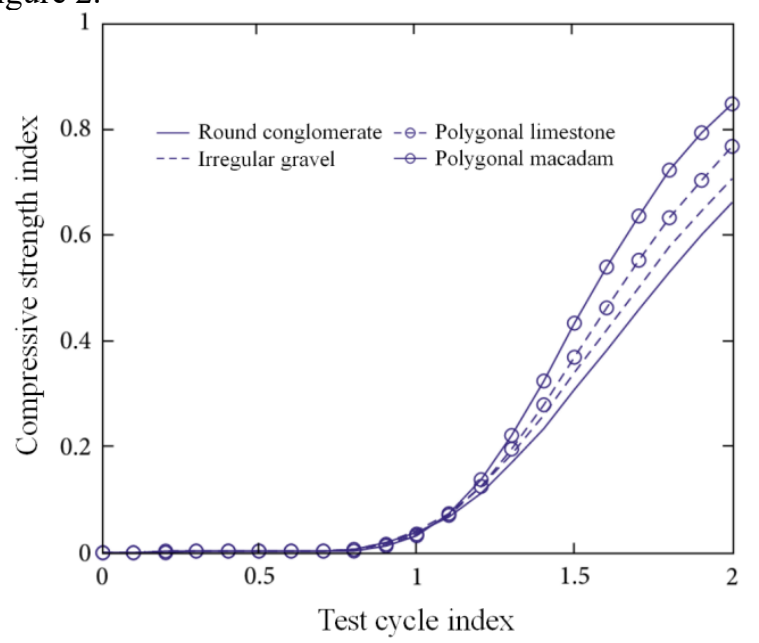

Fig. 2 Relationship between compressive strength and age of concrete prepared with different aggregates

Under the same curing age condition, the compressive strength of the fiber increases with the increase of fiber content. In order to segment them 
accurately, high-energy synchrotron radiation sources are often needed. FRC can not achieve complete interruption during service, so the adjusted definition is not practical. The tensile force of concrete is transferred to the fiber, which leads to the failure of the combination between the fiber and concrete gas and the relative sliding. In the area with high density of hydration products, the hydration products are wrapped around the cement particles, which hinders the hydration reaction and is not conducive to the development of later strength. Fillability is an important index to evaluate the operability of HPC. In the case of special requirements or complex reinforcement, the filling ability of concrete mixture determines the quality after curing. When the material cracks for the first time, the corresponding deflection value is small, and the deflection measurement is easy to be affected by the external additional deformation, so the deflection value of the material at the first crack is not easy to obtain accurately. The research shows that the measurement results of different laboratories or experimental machines are quite different. After pouring concrete, plastic film shall be used to cover the concrete [14]. Then cover the concrete with sacks, Mats and other moisturizing materials, and start watering and curing after the concrete solidifies. When a large amount of superplasticizer is injected, the concrete still has great fluidity under the condition of low gelatin ratio. It can form dense, high strength and high performance concrete with good production strength and durability. When preparing high strength concrete, the content of superplasticizer should be close to or equal to the saturation amount. It is a natural responsibility for material workers to make effective use of natural resources, reduce the pressure of materials on the environment, and maintain a balance of resources in the process of production, use and waste.

\section{Conclusions}

With the continuous development of human society and the continuous progress of science and technology, more and more high-rise structures, long-distance structures and heavy machinery structures are presented in modern architectural models, which require higher and higher working and mechanical properties of materials. Adding fiber can greatly improve the impact energy consumption of concrete, the impact times of early cracks and final cracks increase obviously, and the impact times of final cracks are more, so the ductility of fiber concrete is better. Rigid fiber is more suitable for improving the mechanical properties of concrete, while flexible fiber is more suitable for improving the toughness and durability of concrete. The foundation of concrete strength depends on the strength and cooperation of various components, and the development of concrete strength depends on curing age, curing temperature and humidity. The strength of high performance concrete is inversely proportional to the total shrinkage. The higher the strength, the smaller the total shrinkage. However, if the initial strength of concrete is continuously improved, the initial shrinkage of high performance concrete will also increase accordingly. Ultra-high performance fiber concrete not only provides higher mechanical properties than ordinary concrete, but also has excellent working performance and excellent durability, and has broad application prospects.

\section{Acknowledge}

This paper is supported by the Science and technology program of Hubei Province: Mechanical behavior of ultra high performance concrete based on nano indentation(Project Number: 2018CFC894)

\section{Reference}

1. Cheng Jun, Liu Jiaping, Liu Jianzhong, et al. Research on mechanical properties and mechanism analysis of ultra-high performance concrete with coarse aggregates[J]. Materials Review, 2017, 31(023): 115-119.

2. Yu Ze, Yan Ruizhen. High-temperature mechanical properties and micro-pore structure test of polypropylene blended concrete[J]. Civil Engineering, 2020, 009(002): 91-99.

3. Lu Xinmin, Chen Guoxin, Wang Jiahui, et al. Study on the mechanical properties of fiber-reinforced autoclaved aerated concrete blocks[J]. Concrete, 2015, 02(2):114-114.

4. Liu Weibao, Lu Cairong, Mei Guoxing, et al. Mechanics and durability of fiber high performance concrete[J]. Journal of Civil Engineering and Management, 2017, 34(002): 37-40.

5. Jiao Hua, Han Zhenyu, Chen Xinming, et al. The influence mechanism of basalt fiber on the mechanical properties and microstructure of shotcrete[J]. Journal of Composite Materials, 2019, 36(8):1926-1934.

6. Fu Jian. The effect of different fibers on the durability and microstructure of high-performance concrete[J]. New Building Materials, 2020, 047(004):34-38.

7. Gao Xiaojian, Li Shuangxin. The effect and mechanism of microwave curing on the mechanical properties of ultra-high performance concrete mixed with slag[J]. Materials Review, 2019, 033(002):271-276

8. Lin Jiafu. Research on the mechanical properties and microstructure of basalt fiber reinforced concrete based on SEM[J]. Construction Technology, 2018, 47(18):97-101.

9. Lv Xingdong, Gao Zhiyang, Dong Yun, et al. Study on the effect of anti-seepage and anti-cracking agent and PVA fiber on the performance and microstructure of concrete[J]. Hydropower, 2019, 045(004):116-119.

10. Xue Gang, Zhang Xia. The influence of steel fiber content on the basic mechanical properties of reactive powder concrete[J]. Bulletin of the Chinese Ceramic Society, 2018, 37(3): 934-938.

11. Su Chunlei. Study on the mechanical properties of 
fiber hybrid reinforced reactive powder concrete with different elastic modulus[J]. Comprehensive Utilization of Fly Ash, 2020, 034(001):81-84.

12. Wang Zhenshan, Li Haowei, Wu Bo, et al. Experimental study on alkali corrosion resistance and mechanical properties of basalt fiber concrete[J]. Chinese Journal of Applied Mechanics, 2019, 159(05): 102-109+272-273.

13. Li Xueying, Ma Qinyong. Performance test and analysis of hybrid fiber self-compacting concrete[J]. Science Technology and Engineering, 2019, 019(024):359-364.

14. Zhang Pu, Wang Erli, Xia Yang, et al. Research progress on hydration, microstructure and mechanical properties of ultra-high performance concrete[J]. Civil Engineering, 2018, 007(002):194-204. 